\title{
Cannulated screw and Kirschner fixation for the treatment of medial and lateral malleolar epiphyseal fractures in children: a retrospective study of 36 cases
}

\author{
Linjun Jiang, Jun Wu, Ming Li, Xing Liu, Cong Luo and Xiangyang Qu*
}

\begin{abstract}
Background: Percutaneous fixation with cannulated screws is an effective method for treating medial malleolar epiphyseal fractures, which comprise a portion of bimalleolar and trimalleolar fractures. Lateral malleolar fractures also need to be fixed to achieve anatomical reduction and absolute stable fixation of the ankle. However, there are no individual studies in the literature on this topic.

Methods: Thirty-six children (22 boys and 14 girls) aged 8 to 15 years (average, 11.3 years) with medial and lateral epiphyseal fractures were treated by cannulated screw and Kirschner fixation after closed reduction from January 2010 to December 2015 in our hospital. The patients were examined each month postoperatively. Ankle function was assessed using the Baird-Jackson ankle score.

Results: The 36 patients were followed up for 18 to 29 months (average, 25 months). No cases of fracture non-union or secondary displacement were observed, and the healing time was $2.8 \pm 1.1$ months (range, 2-4 months). At the last follow-up visit, the Baird-Jackson ankle score ranged from 83 to 100 (average, 94), including an "excellent" score in 13 cases, a "good" score in 19 cases, a "fair" score in 4 cases, and a "poor" score in 0 cases. The ankle recovered to the preinjury level of function within $3.5 \pm 1.6$ months (range, 2-5 months). Dysfunction, pain, instability, and premature epiphyseal closure were not observed during the follow-up of the 36 patients.
\end{abstract}

Conclusions: Cannulated screw and Kirschner fixation after closed reduction is an effective and readily available method for the treatment of medial and lateral malleolar epiphyseal fractures in children.

Keywords: Epiphysis, Injury, Percutaneous fixation, Minimally invasive, Ankle, Bone union

\section{Background}

Malleolar epiphyseal fracture is one of the most common clinical injuries of the ankle joint, accounting for approximately $11 \%$ of epiphyseal injuries in children [1-3]. It is considered a "threatening fracture" because the injury mechanism of the distal epiphysis of the tibia and fibula is very complex, and many ankle ligaments are attached at the medial and lateral malleoli.

\footnotetext{
* Correspondence: draxy04090@126.com

Department of Orthopaedics, Children's Hospital of Chongqing Medical University, Ministry of Education Key Laboratory of Child Development and Disorders, Chongqing Engineering Research Center of Stem Cell Therapy, China International Science and Technology Cooperation base of Child Development and Critical disorders, 136\# Zhongshan 2 Road, Yuzhong District, Chongqing 400014, People's Republic of China
}

Epiphyseal injuries often cause early arthrosis, joint deformity, and leg length discrepancies [4-6]. Therefore, epiphyseal fractures with more than $2 \mathrm{~mm}$ of displacement require surgical treatment to maintain the reduced position of the fracture and/or articular surface, in addition to aiding bone healing $[4,7,8]$.

Several types of implants have been used for the anatomical reduction of malleolar epiphyseal fractures, including Kirschner wires, metallic screws, and bioabsorbable screws $[4,9,10]$. Each implant has advantages and disadvantages. Kirschner wires are smooth and cause minimal damage to the epiphysis, but they cannot be used for compression [9]. Therefore, Kirschner wires are typically used to assist in fracture reduction and

(c) The Author(s). 2019 Open Access This article is distributed under the terms of the Creative Commons Attribution 4.0 International License (http://creativecommons.org/licenses/by/4.0/), which permits unrestricted use, distribution, and 
serve as guides for cannulated screws. Metallic screws and bioabsorbable screws are useful for compression to maintain the reduced position. A retrospective study conducted by Podeszwa et al. indicated that similar results were achieved using metallic screws and bioabsorbable screws in the treatment of malleolar physeal fractures [10]. Bioabsorbable screws eliminate the need for epiphyseal screw removal; however, to date, there have been limited clinical results regarding the application of this method for treating malleolar epiphyseal fractures [11]. Fixation with metallic screws is the most widely used method for treating malleolar epiphyseal fractures.

Percutaneous fixation with cannulated screws is a minimally invasive osteosynthesis technique that offers simple operation and the reliable fixation of malleolar epiphyseal fractures, which has been confirmed in many studies [12-14]. Usually, one or two cannulated screws are placed across the fracture in the medial malleolus parallel to the physeal line [9]. However, medial malleolar epiphyseal fractures comprise only a portion of bimalleolar or trimalleolar fractures [1]. Lateral malleolar fractures also need to be fixed to achieve anatomical reduction and absolutely stable fixation of the ankle [15]. Lateral malleolar fractures are usually fixed with a smooth percutaneous Kirschner wire along the radial axis. However, there are no individual studies in the literature on this topic.

Over a period of 6 years, 36 children with medial and lateral malleolar epiphyseal fractures were treated with cannulated screw and Kirschner fixation after closed reduction in our hospital and were followed up for an average of 2.1 years. In this study, we present their outcomes to evaluate the clinical effects of cannulated screw and Kirschner fixation after closed reduction for the treatment of medial and lateral malleolar epiphyseal fractures in children.

\section{Methods \\ Patients}

This study was approved and supervised by the ethics committee of the Children's Hospital of Chongqing Medical University and was performed in accordance with the ethical standards of the 1964 Declaration of Helsinki. Ninety-eight consecutive cases of medial and lateral epiphyseal fractures were treated from January 2010 to December 2015 in the Children's Hospital of Chongqing Medical University. Non-displaced malleolar epiphyseal fractures can be managed conservatively. Reduction was performed when the displacement was greater than $2 \mathrm{~mm}$, and open reduction was performed when an adequate anatomical reduction could not be achieved by closed reduction. If the fractures were unstable or at a high risk of secondary displacement, internal fixation was used $[4,7,8,16]$. Thirty-six of these 98 patients were treated by cannulated screw and Kirschner fixation after closed reduction and were included in the study. The other 62 patients, who were managed conservatively or treated by closed reduction and plaster external fixation or open reduction and internal fixation, were excluded from this study. The guardians of the children provided written informed consent before participation in the study to authorize the publication of the results and the use of photographs of their children.

Patient information is shown in Table 1 . The 36 patients ( 22 boys and 14 girls) were aged 8 to 15 years (average, 11.3 years). The etiology of the fractures was a fall injury in 25 cases and a traffic accident injury in 11 cases. The fractures were categorized according to the Salter-Harris classification system. In this study, all of the medial malleolar epiphyseal fractures were type III, 11 of the 36 lateral malleolar epiphyseal fractures were type I, and the other 25 lateral malleolar epiphyseal fractures were type II.

\section{Surgical procedure}

The surgical procedure was performed according to the Özgür Çiçekli method, which has previously been described in detail [9]. The patients were placed in a supine position, and satisfactory general anesthesia was induced. The affected extremity was draped in a sterile manner. Subsequently, closed reduction was performed. The assistant held the knee of the children against the traction, and the surgeon gripped the distal foot for axial traction. To prevent rotation, the foot was allowed slight plantar flexion under moderate traction intensity. According to the fracture displacement direction and the reverse mechanism of injury, the surgeon pushed the medial or lateral malleolus while pronating or supinating, adducting or abducting, and plantarflexing or dorsiflexing the ankle to reduce the medial and lateral malleolar fractures and achieve a smooth articular surface. After satisfactory reduction was achieved, the

Table 1 Patients' information $(n=36)$

\begin{tabular}{ll}
\hline Subject & Results \\
\hline Age (year) & $11.3(8 \sim 15)$ \\
Sex $(n)$ & Boy to girl 22:14 \\
Etiology $(n)$ & Fall injury 25 \\
& Traffic injury 11 \\
Side $(n)$ & Right to left 14:22 \\
Time to fixation (day) & $3.7(0.5 \sim 6)$ \\
Number of screws $(n)$ & Single to two 23:13 \\
Length of screws $(\mathrm{mm})$ & $32 \sim 36$ \\
Follow-up (month) & $25(18 \sim 29)$ \\
\hline
\end{tabular}


medial fractures were temporarily fixed with 1 or 2 guide wires (diameter, 1.0 or $1.5 \mathrm{~mm}$, Treu-Instrumente $\mathrm{GmbH}$, Germany). C-arm X-ray equipment was used to confirm that the guide wire was placed perpendicular to the fracture line and parallel to the physeal line. The cortex was drilled with a cannulated drill in the anterograde direction over the guide wire. Then, cannulated screws (Treu-Instrumente $\mathrm{GmbH}$, Germany) with a diameter of 3 to $5 \mathrm{~mm}$ were used for percutaneous fixation. The screw thread should penetrate across the fracture line into the lateral cortex of the distal tibia but should not damage the articular surface or the epiphyseal plate. The lateral malleolar fractures were axially fixed with a smooth percutaneous Kirschner wire (diameter, 1.0 or $1.5 \mathrm{~mm}$, Treu-Instrumente $\mathrm{GmbH}$, Germany) along the radial axis. C-arm X-ray equipment was used to confirm satisfactory fracture reduction and reliable internal fixation.

\section{Follow-up}

All 36 patients were treated with postoperative external fixation of the ankle in the functional position with a plaster cast or brace. The children performed guided flexion and extension exercises of the hip and knee

Table 2 Baird-Jackson ankle score

\begin{tabular}{|c|c|c|c|}
\hline Criteria & Severity & Score & Cases \\
\hline \multirow[t]{5}{*}{ Pain } & Without pain & 15 & 27 \\
\hline & Mild pain with strenuous activity & 12 & 9 \\
\hline & Mild pain with activities of daily living & 8 & 0 \\
\hline & Pain with weight bearing & 4 & 0 \\
\hline & Pain at rest & 0 & 0 \\
\hline \multirow[t]{3}{*}{ Stability } & No clinical instability & 15 & 36 \\
\hline & Instability with sports activities & 5 & 0 \\
\hline & Instability with activities of daily living & 0 & 0 \\
\hline \multirow[t]{5}{*}{ Ability to walk } & Able to walk desired distances without limp or pain & 15 & 30 \\
\hline & Able to walk desired distances with slight pain & 8 & 6 \\
\hline & Moderate restriction in ability to walk, with mild pain & 6 & 0 \\
\hline & Able to walk short distances only & 3 & 0 \\
\hline & Unable to walk & 0 & 0 \\
\hline \multirow[t]{5}{*}{ Ability to run } & Able to run desired distances without limp or pain & 10 & 12 \\
\hline & Able to run desired distances with slight pain & 8 & 23 \\
\hline & Moderate restriction in ability to run, with mild pain & 6 & 1 \\
\hline & Able to run short distances only & 3 & 0 \\
\hline & Unable to run & 0 & 0 \\
\hline \multirow[t]{5}{*}{ Ability to work } & Able to perform usual occupation without restrictions & 10 & 22 \\
\hline & Able to perform usual occupation with restrictions in some strenuous activities & 8 & 13 \\
\hline & Able to perform usual occupation with substantial restrictions & 6 & 1 \\
\hline & Partially disabled, select jobs only & 3 & 0 \\
\hline & Unable to work & 0 & 0 \\
\hline \multirow[t]{4}{*}{ Motion of ankle } & Within $10^{\circ}$ of uninjured ankle & 10 & 25 \\
\hline & Within $15^{\circ}$ of uninjured ankle & 7 & 10 \\
\hline & Within $20^{\circ}$ of uninjured ankle & 4 & 1 \\
\hline & $<50 \%$ of uninjured ankle & 0 & 0 \\
\hline \multirow[t]{5}{*}{ Radiographic result } & Anatomic with intact mortise & 25 & 34 \\
\hline & Mild reactive changes at joint margins & 15 & 2 \\
\hline & Measurable narrowing of superior joint space, with superior joint space $>2 \mathrm{~mm}$ & 10 & 0 \\
\hline & Moderate narrowing of superior joint space, with superior joint space 1 to $2 \mathrm{~mm}$ & 5 & 0 \\
\hline & $\begin{array}{l}\text { Severe narrowing of superior joint space, with joint space }<1 \mathrm{~mm} \text {, widening of medial } \\
\text { clear space, or severe reactive changes (subchondral sclerosis and osteophyte formation) }\end{array}$ & 0 & 0 \\
\hline
\end{tabular}


starting from the first postoperative day. The external fixation support was removed after 3-6 weeks (average, 4 weeks), and functional training was started under physician guidance. The patients were followed up every month for the first 3 months, every 3 months for the first year, and then every 6 months for the second and third postoperative years. Walking with full weight bearing was not allowed until the fractures showed bony healing. Ankle function was assessed using the Baird-Jackson ankle score [17]. The maximum possible score was 100 , including 15 points for ankle pain, 15 points for ankle stability, 15 points for the ability to walk, 10 points for the ability to run, 15 points for ankle motion, and 25 points for the radiographic results. A total score from 96 to 100,91 to 95,81 to 90 , and less than 80 was considered excellent, good, fair, and poor, respectively.

\section{Results}

The time from injury to surgical operation ranged from $12 \mathrm{~h}$ to 6 days (average, 3.7 days). Twenty-three medial malleolar fractures were treated with a single screw, while the other 13 were treated with two screws. The screws used in this study ranged from 32 to $36 \mathrm{~mm}$ in length. The 36 patients were followed up for 18 to 29 months (average, 25 months). Among them, 1 patient experienced numbness of the medial foot, which was caused by local cutaneous nerve stimulation and interference of the implanted screws. The symptom disappeared spontaneously within 2 weeks after the operation. No cases of fracture non-union or secondary displacement were observed. The cannulated screws and Kirschner wires were extracted at $2.8 \pm 1.1$ months (range, 2-4 months) after surgery when the fractures had healed. At the last follow-up visit, the Baird-Jackson ankle score ranged from 83 to 100 (average, 94). According to the total Baird-Jackson ankle score, the functional outcomes were rated as "excellent" in 13 cases, "good" in 19 cases, "fair" in 4 cases, and "poor" in 0 cases (Fig. 3 and Table 2). The ankle recovered to the pre-injury level of function within $3.5 \pm 1.6$ months (range, $2-5$ months). Premature physeal closure (PPC) or ankle deformities were not observed in any patients at the last follow-up visit. A typical case was shown in Figs. 1, 2 and 3.

\section{Discussion}

The ankle joint is a tongue-like joint with primarily vertical movement consisting of plantar flexion and dorsiflexion in one plane. Only the lateral malleolus can slightly rotate to accommodate variations in the width of the top of the talus. The medial and lateral malleoli are attached by numerous ankle ligaments around the joints. Because of the anatomy and limited range of motion of the ankle joint, the epiphysis of the distal tibia, especially the medial malleolus, often

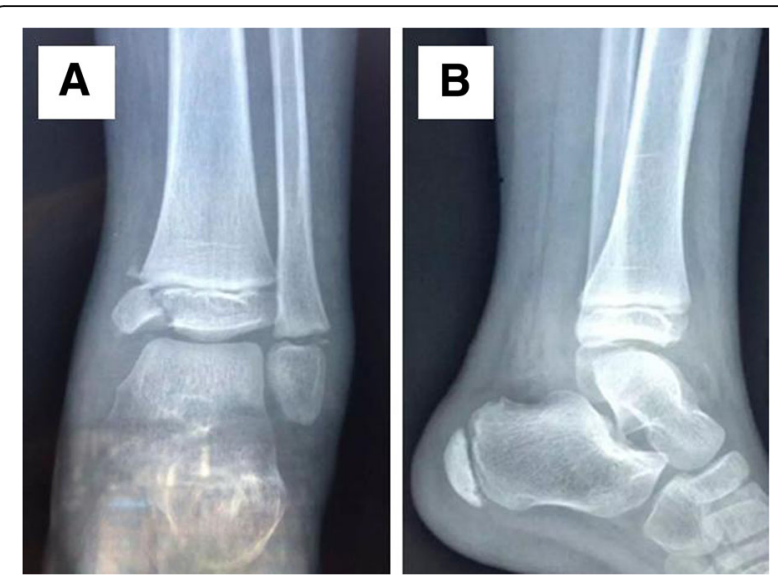

Fig. 1 Preoperative $X$-rays (a, the anteroposterior film, b, the lateral film) of a 5-year-old boy with medial malleolus epiphyseal fracture (Salter-Harris III) and lateral malleolus epiphyseal fracture (SalterHarris I) in right ankle joint

suffers sprain and extrusion. When the foot is fixed, external forces causing varus or valgus movement, plantar flexion, dorsiflexion, or external rotation of the foot can all cause injury to the epiphysis of the distal tibia [18]. In children, the epiphyseal plate is particularly susceptible to injury during the skeletal developmental stages because the epiphyseal plate connection is a mechanically weak zone. Among epiphyseal injuries in children, those to the distal tibia and fibula are considered "threatening fractures" because the injury severity and treatment efficacy directly affect the late functional morphology and development of the ankle $[19,20]$. Any damage can cause partially or fully closed epiphyseal plates, resulting in late limb shortening or deformity. According to the Salter-Harris epiphyseal injury classification

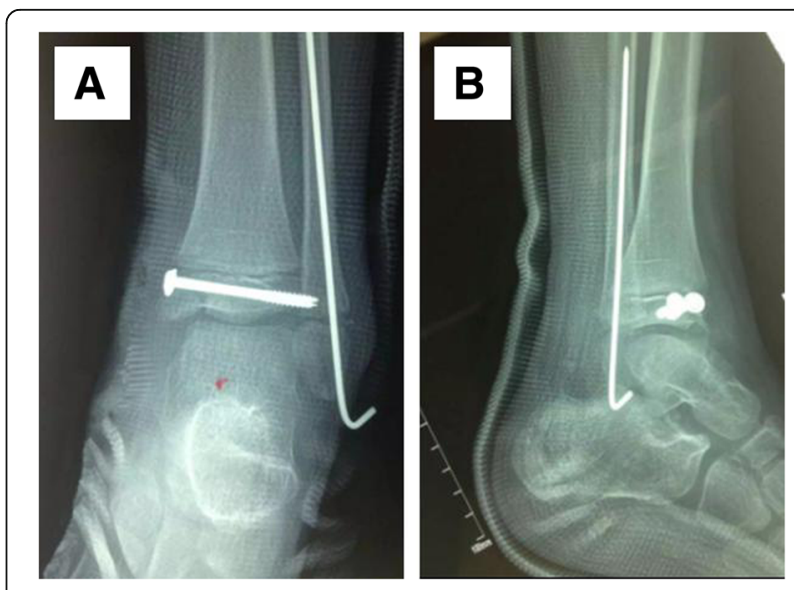

Fig. 2 Early postoperative X-rays (a, the anteroposterior film, $\mathbf{b}$, the lateral film) of the child in Fig. 1. The medial malleolus fracture was fixed with two cannulated screws, and the lateral malleolus fracture was fixed with a Kirschner wire along the radial axis 

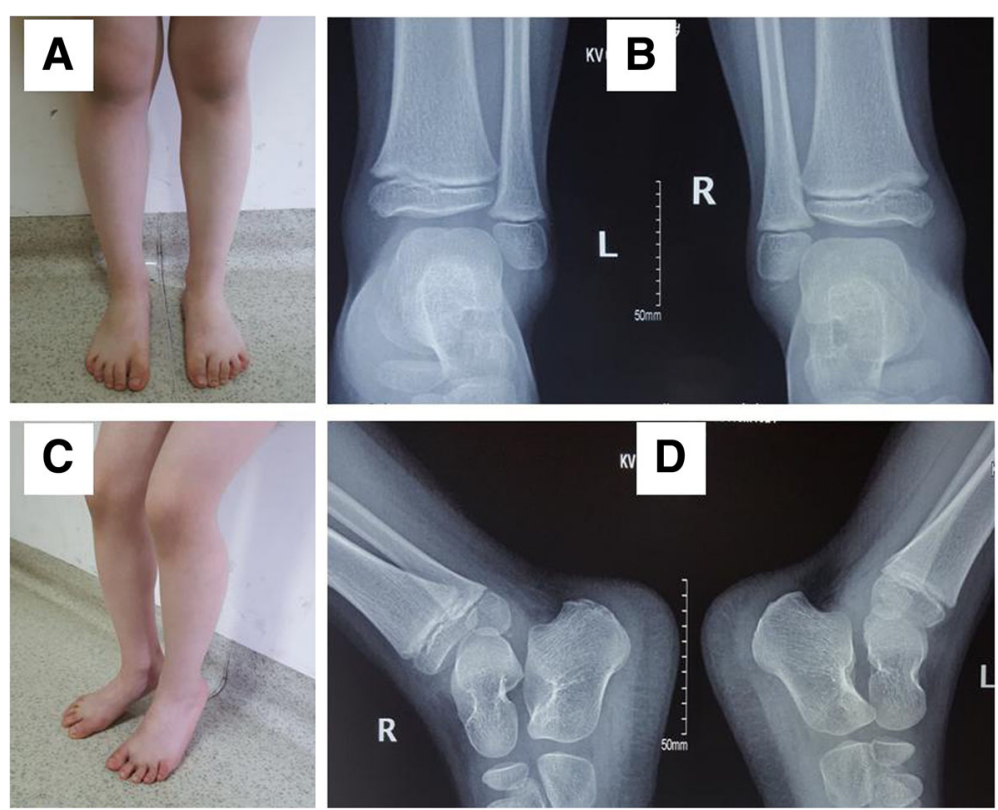

Fig. 3 General observation $(\mathbf{a}, \mathbf{c})$ and X-rays $(\mathbf{b}, \mathbf{d})$ of the patient in Fig. 1 at postoperative 2 years indicating that the fracture had healed and ankle joint function had restored

criteria, the medial malleolar fractures in the included cases involved partial epiphyseal separation with epiphyseal fracture, leading to a joint cavity; these fractures are type III epiphyseal injuries and are considered intra-articular fractures. Fracture displacement can cause articular surface irregularities and mismatch between the ankle mortise and talus because of the role of external forces and stretching of the attached ligaments. The reduced fracture may be unstable and cause late redisplacement, which can in turn result in malunion. Therefore, medial malleolar fractures often require anatomical reduction and effective fixation. The lateral malleolar fractures of the included cases were type I epiphyseal injuries with epiphyseal separation. These fractures generally do not involve damage to the articular surface and cause relatively minor displacement compared to medial malleolar fractures. The cases included in this study included medial malleolar fractures with significant displacement involving the articular surface, accompanied by lateral malleolar fractures with relatively minor displacement and no involvement of the articular surface. These findings are consistent with the injury mechanism, the characteristics of the ankle joint anatomy, and the characteristics of medial and lateral malleolar epiphyseal fractures.

The selection of a treatment for medial and lateral malleolar epiphyseal fractures is very important for functional ankle recovery in children. The epiphysis is not only the point of bone growth in children but also a weak area prone to injury under external forces. A personalized and selective approach for the treatment of medial and lateral malleolar fractures should be applied based on various factors, such as the degree of fracture displacement and the severity of accompanying local injury to soft tissue. Non-displaced malleolar epiphyseal fractures can be managed conservatively, and the tube or " $U$ "-shaped plaster fixation needs to be replaced after the swelling has subsided. Reduction was performed when the displacement was greater than $2 \mathrm{~mm}$, and open reduction was performed when an adequate anatomical reduction could not be achieved with closed reduction. If the fractures were unstable or at a high risk of secondary displacement, internal fixation was adopted. Moreover, open reduction and internal fixation were performed when the fractures were accompanied by open wounds, ankle dislocation, or severe ligament injury or in fractures associated with blood vessel and nerve injury $[4,7,8,16,21]$. In the present study, medial and lateral malleolar epiphyseal fractures with displacements of more than $2 \mathrm{~mm}$ were treated by cannulated screw and Kirschner fixation after closed reduction. Closed reduction and internal fixation can effectively reduce and fix fractures, does not cause additional injury to the local soft tissue and periosteum, and only slightly interferes with fracture healing. Therefore, it shortens the healing time and allows the early recovery of limb function [22].

The most common and important complication of distal tibia physeal fracture is PPC [21]. As shown in Table 3, the incidence of PPC ranges from 0.5 to $43 \%$ $[2,9,16,21,23-26]$. The factors that contribute to the development of PPC are still controversial. Özgür 
Table 3 The studies on pediatric epiphyseal ankle fractures and premature physeal closure (PPC)

\begin{tabular}{|c|c|c|c|c|c|c|c|}
\hline Study & $\begin{array}{l}\text { Number of } \\
\text { patients }(n)\end{array}$ & $\begin{array}{l}\text { Mean age } \\
\text { (years) }\end{array}$ & $\begin{array}{l}\text { Follow-up } \\
\text { (years) }\end{array}$ & $\begin{array}{l}\text { PPC } \\
(n)\end{array}$ & $\begin{array}{l}\text { Factors associated } \\
\text { with PPC }\end{array}$ & $\begin{array}{l}\text { Factors do not } \\
\text { induce PPC }\end{array}$ & $\begin{array}{l}\text { Malformation } \\
(n)\end{array}$ \\
\hline Russo et al. [23] & 96 & 12.6 & Mean 0.6 & 40 & Mechanism of injury & $\begin{array}{l}\text { Primary fracture } \\
\text { displacement } \\
\text { Associated distal } \\
\text { fibular fracture }\end{array}$ & 1 \\
\hline $\begin{array}{l}\text { Özgür Çiçekli } \\
\text { et al. [9] }\end{array}$ & 24 & 12.3 & Mean 1.1 & 3 & Mechanism of injury & & 0 \\
\hline Leary et al. [24] & 124 & 12.5 & Mean 1.1 & 15 & $\begin{array}{l}\text { Mechanism of injury } \\
\text { Primary fracture displacement }\end{array}$ & & 5 \\
\hline Seel et al. [25] & 225 & 12.5 & Mean 5.7 & 12 & $\begin{array}{l}\text { Associated distal fibular fracture } \\
\text { Good anatomical reduction }\end{array}$ & $\begin{array}{l}\text { Mechanism of injury } \\
\text { Primary fracture displacement } \\
\text { Residual displacement after } \\
\text { reduction } \\
\text { Treatment modality }\end{array}$ & 6 \\
\hline Cai et al. [2] & 286 & 11.7 & Mean 6.4 & 42 & Associated distal fibular fracture & $\begin{array}{l}\text { Primary fracture displacement } \\
\text { Residual displacement after } \\
\text { reduction }\end{array}$ & 16 \\
\hline $\begin{array}{l}\text { D'Angelo } \\
\text { et al. [16] }\end{array}$ & 46 & 11 & More than 2 & 1 & $\begin{array}{l}\text { Associated distal fibular fracture } \\
\text { Good anatomical reduction }\end{array}$ & & 1 \\
\hline Schurz et al. [26] & 195 & 11.6 & Mean 0.2 & 1 & Good anatomical reduction & & 1 \\
\hline
\end{tabular}

Çiçekli et al., Russo et al., and Leary et al. found that PPC was significantly associated with the mechanism of injury $[9,23,24]$, while Seel et al. found no significant link between the mechanism of injury and PPC [25]. Leary et al. demonstrated that the primary fracture displacement had a significant influence on PPC [24], but this was disapproved by other studies $[2,23,25]$. Many studies have confirmed that fibula fracture is an important risk factor for the development of PPC, which furthermore indicates that good anatomical reduction may reduce the rate of PPC $[2,16,25,26]$. In this study, medial malleolar fractures were treated by cannulated screws after closed reduction, and lateral malleolar fractures were effectively fixed by the axial implantation of a smooth Kirschner wire. PPC or ankle deformities did not occur in this study. Because this study is limited by its retrospective nature, and only children treated by cannulated screw and Kirschner fixation after closed reduction were included, a prospective randomized controlled study should be performed to confirm the clinical efficacy and investigate the factors associated with complications.

\section{Conclusions}

In this study, cannulated screw and Kirschner fixation after closed reduction was used to treat medial and lateral malleolar epiphyseal fractures in children, and the results confirmed a high rate of union and satisfactory functional outcomes without complications. Hence, cannulated screw and Kirschner fixation after closed reduction is an effective and readily available method for treating medial and lateral malleolar epiphyseal fractures in children.

\section{Acknowledgements}

We thank all of the patients involved in the study. We thank the Department of Radiology of the Children's Hospital of Chongqing Medical University for providing X-ray images.

\section{Authors' contributions}

$\mathrm{XQ}$ contributed to the study design and is the corresponding author. $\mathrm{LJ}$ contributed to the study design, data analysis and interpretation, and manuscript draft. JW contributed to the data collection and analysis. ML contributed to the data collection and analysis. $\mathrm{XL}$ contributed to the literature search and manuscript revision. $\mathrm{CL}$ contributed to the literature search and manuscript revision. All authors have read and approved the final manuscript.

\section{Funding}

No funding was provided.

\section{Availability of data and materials}

The datasets analyzed in the study are available from the corresponding author on reasonable request.

\section{Ethics approval and consent to participate}

This study was approved and supervised by the ethics committee of the Children's Hospital of Chongqing Medical University and was performed in accordance with the ethical standards of the 1964 Declaration of Helsinki. Informed written consent was obtained from all patients.

\section{Consent for publication}

The subject shown in Figs. 1, 2, and 3 and his parents provided their written informed consent for publication of the images.

\section{Competing interests}

The authors declare that they have no competing interests.

Received: 11 January 2019 Accepted: 23 July 2019

Published online: 08 August 2019

\section{References}

1. Rosenbaum AJ, Dipreta JA, Uhl RL. Review of distal tibial epiphyseal transitional fractures. Orthopedics. 2012;35(12):1046-9.

2. Cai H, Wang Z, Cai H. Surgical indications for distal tibial epiphyseal fractures in children. Orthopedics. 2015;38(3):e189. 
3. Mizuta T, Benson WM, Foster BK. Statistical analysis of the incidence of epiphyseal injuries. J Pediatr Orthop. 1987;7:518-23.

4. Wuerz TH, Gurd DP. Pediatric physeal ankle fracture. J Am Acad Orthop Surg. 2013;21(4):234-44.

5. Kay RM, Matthys GA. Pediatric ankle fractures: evaluation and treatment. J Am Acad Orthop Surg. 2001;9(4):268-78.

6. Denning JR. Complications of pediatric foot and ankle fractures. Orthop Clin N Am. 2017:48(1):59.

7. Li Y, Jiang $X$, Guo Q, et al. Treatment of distal tibial shaft fractures by three different surgical methods: a randomized, prospective study. Int Orthop. 2014;38(6):1261-7.

8. Su AW, A Noelle L. Pediatric ankle fractures: concepts and treatment principles. Foot Ankle Clin. 2015;20(4):705-19.

9. Çiçekli Ö, Özdemir G, Uysal M, et al. Percutaneous cannulated screw fixation for pediatric epiphyseal ankle fractures. Springerplus. 2016:5(1):1925.

10. Podeszwa DA, Wilson PL, Holland AR, et al. Comparison of bioabsorbable versus metallic implant fixation for physeal and epiphyseal fractures of the distal tibia. J Pediatr Orthop. 2008;28(8):859-63.

11. Joukainen A, Partio EK, Waris $P$, et al. Bioabsorbable screw fixation for the treatment of ankle fractures. J Orthop Sci. 2007;12(1):28-34.

12. Charlton M, Podeszwa DA. Ankle joint biomechanics following transepiphyseal screw fixation of the distal tibia. J Pediatr Orthop. 2005; 25(5):635-40.

13. Podeszwa DA, Mubarak SJ. Physeal fractures of the distal tibia and fibula (Salter-Harris type I, II, III, and IV fractures). J Pediatr Orthop. 2012; 32(Suppl 1):S62

14. Tekin AÇ, Çabuk H, Dedeoğlu SS, et al. Anterograde headless cannulated screw fixation in the treatment of medial malleolar fractures: evaluation of a new technique and its outcomes. Med Princ Pract. 2016;25(5):429.

15. Latif $\mathrm{G}$, Alsaadi $\mathrm{H}$, Zekry $\mathrm{M}$, et al. The effect of percutaneous screw fixation of lateral malleolus on ankle fracture healing and function. Surg Sci. 2013; 4(8):365-70

16. D'Angelo F, Solarino $G$, Tanas $D$, et al. Outcome of distal tibia physeal fractures: a review of cases as related to risk factors. Injury. 2017; 48(Suppl 3):s7-s11.

17. Zhou Q, Lu H, Wang Z, et al. Posterolateral approach with buttress plates and cannulated screw fixation for large posterior malleolus fractures. J Foot Ankle Surg. 2017;56(6):1173.

18. Matuszewski PE, Dombroski D, Lawrence JT, et al. Prospective intraoperative syndesmotic evaluation during ankle fracture fixation: stress external rotation versus lateral fibular stress. J Orthop Trauma. 2015:29(4):157-60.

19. Nenopoulos SP, Papavasiliou VA, Papavasiliou AV. Outcome of physeal and epiphyseal injuries of the distal tibia with intra-articular involvement. J Pediatr Orthop. 2005:25:518-22.

20. Rohmiller MT, Gaynor TP, Pawelek J. Salter-Harris I and II fractures of the distal tibia: does mechanism of injury relate to premature physeal closure? J Pediatr Orthop. 2006;26:322-8.

21. Asad WA, Younis MHS, Ahmed AF, et al. Open versus closed treatment of distal tibia physeal fractures: a systematic review and meta-analysis. Eur $J$ Orthop Surg Traumatol. 2018;28(3):503-9.

22. Ebraheim NA, Zhang J, Liu J. Preliminary result of percutaneous screw fixation for bone bruise of the tibial plateau. J Orthop. 2015:38(12):747-50

23. Russo F, Moor MA, Mubarak SJ, Pennock AT. Salter-Harris II fractures of the distal tibia: does surgical management reduce the risk of premature physeal closure? J Pediatr Orthop. 2013;33(5):524-9.

24. Leary JT, Handling $M$, Talerico $M$, Yong L, Bowe JA. Physeal fractures of the distal tibia: predictive factors of premature physeal closure and growth arrest. J Pediatr Orthop. 2009;29(4):356-61.

25. Seel EH, Noble S, Clarke NM, Uglow MG. Outcome of distal tibial physeal injuries. J Pediatr Orthop B. 2011;20(4):242-8.

26. Schurz $\mathrm{M}$, Binder $\mathrm{H}$, Platzer $\mathrm{P}$, et al. Physeal injuries of the distal tibia: longterm results in 376 patients. Int Orthop. 2010;34(4):547-52.

\section{Publisher's Note}

Springer Nature remains neutral with regard to jurisdictional claims in published maps and institutional affiliations.

\section{Ready to submit your research? Choose BMC and benefit from:}

- fast, convenient online submission

- thorough peer review by experienced researchers in your field

- rapid publication on acceptance

- support for research data, including large and complex data types

- gold Open Access which fosters wider collaboration and increased citations

- maximum visibility for your research: over $100 \mathrm{M}$ website views per year

At BMC, research is always in progress.

Learn more biomedcentral.com/submissions 